\title{
No monkey business: why studying NK cells in non-human primates pays off
}

\author{
Henoch S. Hong ${ }^{1}$, Premeela A. Rajakumar ${ }^{1}$, James M. Billingsley ${ }^{1}$, R. Keith Reeves ${ }^{1}$ and \\ R. Paul Johnson ${ }^{1,2 *}$ \\ 1 Division of Immunology, New England Primate Research Center, Harvard Medical School, Southborough, MA, USA \\ 2 Infectious Disease Unit, Ragon Institute of Massachusetts General Hospital, MIT and Harvard, Massachusetts General Hospital, Boston, MA, USA
}

\section{Edited by:}

Eric Vivier, Centre d'Immunologie de Marseille-Luminy, France

Reviewed by:

William G. Kerr, SUNY Upstate

Medical University, USA

John T. Vaage, Oslo University

Hospital and University of Oslo,

Norway

*Correspondence:

R. Paul Johnson, Division of

Immunology, New England Primate

Research Center, Harvard Medical

School, One Pine Hill Drive,

Southborough, MA 01772-9102,

USA.

e-mail:paul_johnson@hms.

harvard.edu
Human NK (hNK) cells play a key role in mediating host immune responses against various infectious diseases. For practical reasons, the majority of the data on hNK cells has been generated using peripheral blood lymphocytes. In contrast, our knowledge of NK cells in human tissues is limited, and not much is known about developmental pathways of hNK cell subpopulations in vivo. Although research in mice has elucidated a number of fundamental features of NK cell biology, mouse, and hNK cells significantly differ in their subpopulations, functions, and receptor repertoires. Thus, there is a need for a model that is more closely related to humans and yet allows experimental manipulations. Non-human primate models offer numerous opportunities for the study of NK cells, including the study of the role of NK cells after solid organ and stem cell transplantation, as well as in acute viral infection. Macaque NK cells can be depleted in vivo or adoptively transferred in an autologous system. All of these studies are either difficult or unethical to carry out in humans. Here we highlight recent advances in rhesus NK cell research and their parallels in humans. Using high-throughput transcriptional profiling, we demonstrate that the human CD56 bright and CD56 dim NK cell subsets have phenotypically and functionally analogous counterparts in rhesus macaques. Thus, the use of non-human primate models offers the potential to substantially advance hNK cell research.

Keywords: non-human primate models, rhesus macaques, NK cell subpopulations, transcriptional profiling

\section{INTRODUCTION-THE NEED FOR A BETTER MODEL TO UNDERSTAND HUMAN NK CELLS}

NK cells are lymphocytes that have evolved to provide a first line of immune protection against viruses and malignancies before adaptive immune responses emerge (Lanier, 2008). Increasing evidence suggests that human $\mathrm{NK}(\mathrm{hNK})$ cell contributions to the host defense against viruses are pivotal. People with genetic NK cell deficiencies, though very rare, display severe primary or recurring infections by members of the herpesvirus family (Orange, 2006), suggesting that NK cells are crucial to host defense against viral infections. In addition, epidemiological data suggest a protective role for NK cells in hepatitis $\mathrm{C}$ virus infection (Khakoo et al., 2004) and HIV infection (Martin et al., 2002, 2007). Although these studies suggest that a better knowledge of hNK cells has the potential to be translated into novel, therapeutic approaches, research has been hindered by the limitations of the human "model." Most of our knowledge on hNK cells has been derived from studies performed on peripheral blood lymphocytes due to ease of accessibility. However, NK cells in blood only represent one specialized subset of the total hNK cell compartment. Furthermore, manipulations of the human immune system are either highly challenging and/or unethical to carry out and are thus largely limited to vaccination.
The study of murine NK ( $\mathrm{mNK}$ ) cells has clearly elucidated a number of fundamental principles, some of which seem to universally apply to all NK cells, such as the activation of NK cells by absent or altered MHC class I molecule expression, also known as the "missing self hypothesis" (Karre et al., 1986; Ljunggren and Karre, 1990). Recent pioneering work suggests that mNK cells can exhibit adaptive immune features, a paradigm-altering concept, which has not yet been observed in hNK cells (Sun et al., 2009; Paust et al., 2010). Whereas mice continue to serve as a powerful tool to study basic immunological questions, many research advances made in murine models have not been translated into medical practice (Davis, 2008). In part, this discrepancy may be explained by the substantial differences between mouse and human immunology, which is not surprising given the evolutionary distance of 65-75 million years that separate human and mice development (Mestas and Hughes, 2004), as well as the challenges of modeling human diseases in murine models.

There are a number of important differences between hNK and $\mathrm{mNK}$ cells. In mice, cognate MHC class I molecules are recognized by Ly49 protein family members, which contain C-type lectin domains (Carlyle et al., 2008). In contrast, interactions of hNK cells with classical MHC class I molecules rely primarily on killer cell immunoglobulin-like receptors (KIRs). Although Ly49 proteins and KIRs are functional homologs, they 
are different in almost every other aspect, including structural properties, different binding sites of the MHC class I molecules, and genetic differences (Natarajan et al., 2002; Pascal et al., 2006). Furthermore, despite a remarkably high degree of conservation of NKG2D in humans compared to mice, phylogenetic analyses suggest that the ligands diversified independently from each other (Raulet, 2003; Eagle and Trowsdale, 2007).

Importantly, there are also differences between $\mathrm{hNK}$ and $\mathrm{mNK}$ cell subpopulations. In humans, two phenotypically and functionally distinct peripheral blood NK cell subsets have been described based on the expression of CD56 and CD16 (Caligiuri, 2008). The predominant population of $\mathrm{CD} 16^{+} \mathrm{CD} 56^{\mathrm{dim}} \mathrm{NK}$ cells is known for its cytolytic activity and limited cytokine production (Lanier et al., 1986). In contrast, the less frequent CD56 $6^{\text {bright }} \mathrm{NK}$ cell subset does not express CD16 and is traditionally considered to possess "regulatory" functions (Cooper et al., 2001). Although the use of CD27 and Mac-1 (CD11b) allows mature $\mathrm{mNK}$ cells to be divided into distinct subsets with some parallels to hNK cell subsets (Hayakawa and Smyth, 2006), there remain significant differences between $\mathrm{mNK}$ and hNK cell subpopulations, such as divergent expression of CD62L, CCR7, CX3CR1, and other phenotypic markers (Hayakawa et al., 2006). Also, to our knowledge it is not known whether CD27 $7^{\text {low }}$ NK cells mediate antibodydependent cytotoxic activity as CD56 ${ }^{\mathrm{dim}} \mathrm{NK}$ cells do in humans.

Here, we argue that non-human primate models, such as rhesus macaques, represent a powerful animal model with significant potential for the study of hNK cells for two important reasons. First, rmNK cells exhibit far greater similarities to hNK cells than mNK cells. Second, as an animal model, non-human primates allow ready access to tissues and experimental manipulations that are highly challenging or unethical to carry out in humans.

\section{DEFINING NK CELL SUBPOPULATIONS IN RHESUS MACAQUES}

Unlike hNK cells, virtually all rmNK cells in peripheral blood express CD8 $\alpha$ and most of them do not express CD56 (Carter et al., 1999). In addition, not all peripheral rmNK cells express NKp46 (Reeves et al., 2010) but virtually all of them express NKG2A, which renders this receptor a highly reliable marker for the definition of peripheral rmNK cells (Mavilio et al., 2005a; Webster and Johnson, 2005). Thus, after gating on $\mathrm{CD}^{-} \mathrm{CD} 8 \alpha^{+} \mathrm{NKG} 2 \mathrm{~A}^{+}$cells, analysis of CD56 and CD16 allows the definition of 3 distinct $\mathrm{NK}$ cell subsets in rhesus macaques: $\mathrm{CD}^{+} 6^{+}, \mathrm{CD}^{-} 6^{-} \mathrm{CD} 16^{-}$double-negative (DN), and CD $16^{+} \mathrm{NK}$ cells (Webster and Johnson, 2005; Reeves et al., 2010). Rigorous NK cell phenotyping revealed that the $\mathrm{CD} 56^{+} \mathrm{CD} 16^{-}$population resembles CD56 $6^{\text {bright }} \mathrm{hNK}$ cells, especially with regard to expression of lymph node homing markers, such as CCR7 and CD62L, in addition to lower expression of granzyme B and perforin (Webster and Johnson, 2005; Reeves et al., 2010). Conversely, the $\mathrm{CD}_{16}{ }^{+}$rmNK cell population corresponds well to the CD56 ${ }^{\mathrm{dim}}$ hNK cell subset, as evidenced by the increased expression of granzyme B and perforin and absence of CCR7 and CD62L. A relatively infrequent $\mathrm{CD}_{161^{+}} \mathrm{DN}$ hNK cell population has been defined (Bennett et al., 1996) but it remains unclear whether this population corresponds to the DN rmNK cell subset.

\section{TRANSCRIPTIONAL ANALYSIS REVEALS A HIGH DEGREE OF HOMOLOGY BETWEEN RHESUS AND hNK CELLS}

A previous transcriptome analysis study revealed a number of differentially expressed genes in CD56 $6^{\text {bright }}$ and CD56 ${ }^{\text {dim }}$ hNK cells (Hanna et al., 2004). We therefore tested the notion that CD56 ${ }^{+}$ and $\mathrm{CD} 16^{+}$rmNK cells correspond to CD56 $6^{\text {bright }}$ and CD56 $6^{\text {dim }}$ hNK cells by performing an extensive transcriptional analysis of rmNK cell subpopulations using a high-throughput microfluidics PCR platform (Fluidigm BioMark) on highly purified CD56 ${ }^{+}$, $\mathrm{CD}_{16}{ }^{+}$, and $\mathrm{DN}$ rmNK cells. We either utilized rhesus-specific ABI TaqMan assays, when available, (Life Technologies), or custom-designed primers and probes based on rhesus mRNA sequences. A complete list of real-time PCR assays employed in our study is available upon request. All assays were subjected to a rigorous selection process to ensure that targeted rhesus macaque genes were orthologous to human genes.

Principal component analysis (PCA) revealed a segregation of NK cells into groups corresponding to the $\mathrm{CD}^{+} 6^{+}, \mathrm{CD} 6^{+}$, and DN rmNK cell subsets (Figure 1A). Similar results were observed when we subjected the data to unsupervised hierarchical clustering (data not shown). We analyzed the relative expression of a number of effector proteins and found low expression of the $\beta$-chemokines CCL3, CCL4, and CCL5 in CD56 ${ }^{+}$cells and high expression of these genes in $\mathrm{CD}_{16}{ }^{+}$cells (Figure 1B). Conversely, transcripts for granzyme $\mathrm{K}$ (GZMK) and amphiregulin (AREG) were more abundantly found in $\mathrm{CD}_{5} 6^{+}$cells. We found high mRNA expression of the IL-7R in $\mathrm{CD}^{+} 6^{+}$cells but negligible expression in $\mathrm{CD}^{+} 6^{+}$cells (Figure 1C) as expected based on human microarray and flow cytometric data (Hanna et al., 2004; Vosshenrich et al., 2006). In addition, we were able to identify predicted expression patterns for the tumor necrosis factor receptor superfamily member $1 \mathrm{~B}$ (TNFRSF1B), integrin $\alpha 5$ (ITGA5), CX3CR1, CD53, G protein-coupled receptor 183 (GPR183), and cathepsin W (CTSW) (Figure 1C). Finally, the transcription factors TCF7, ETF1, GATA3, and TCF8 were highly expressed in $\mathrm{CD} 6^{+}$compared to $\mathrm{CD} 16^{+}$rmNK cells, whereas the reverse trend was observed for BATF (Figure 1D).

Notably, the DN NK cell subset represented an intermediate population between $\mathrm{CD}_{5}{ }^{+}$and $\mathrm{CD} 16^{+} \mathrm{NK}$ cells, both in the PCA analysis as well as for most of the gene expression data presented in Figure 1. This is of particular interest since increasing evidence suggests that CD56 $6^{\text {bright }} \mathrm{NK}$ cells represent a less mature developmental stage of NK differentiation, whereas CD56 ${ }^{\text {dim }}$ cells exhibit a more differentiated effector profile (Romagnani et al., 2007; Yu et al., 2010; Beziat et al., 2011). We observed similar patterns in rmNK cells, as evidenced by expression of IL-7R and cKIT (data not shown), and TCF7 in CD56 ${ }^{+}$cells, a pattern consistent with a more primitive stage of differentiation. Conversely, the expression of effector proteins such as CCL3, CCL4, and CCL5 was predominantly found in $\mathrm{CD}_{16}{ }^{+}$cells. In this context, DN NK cells are likely to represent an intermediate stage of NK cell differentiation between $\mathrm{CD}^{+} 6^{+}$and $\mathrm{CD}^{+} 6^{+}$cells. A number of potential candidates have been suggested as intermediate $\mathrm{NK}$ cell populations in humans, including $\mathrm{CD} 16^{+} \mathrm{CD} 56^{\text {bright }}$ cells 


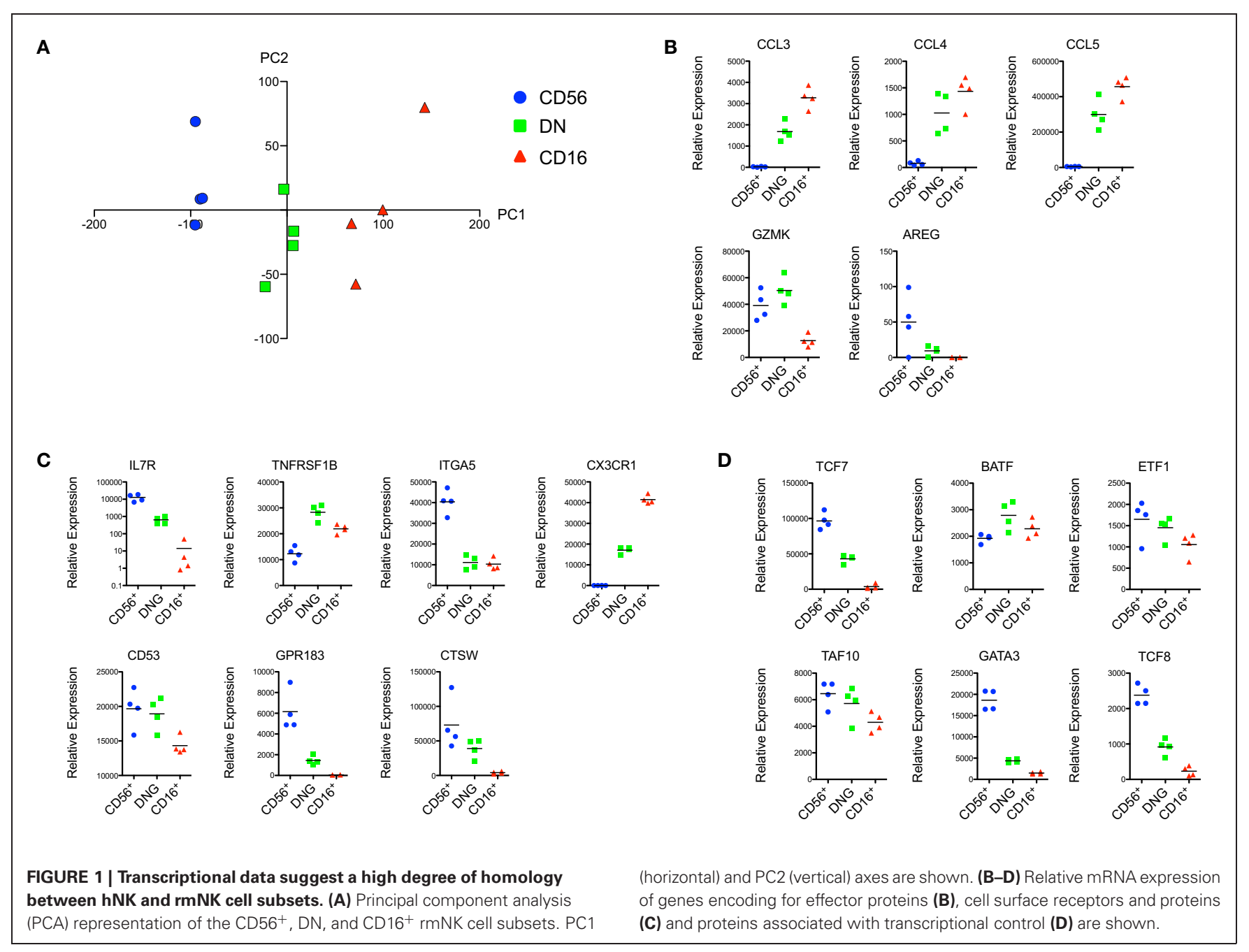

(Beziat et al., 2011), CCR7 ${ }^{-}$CD56 $6^{\text {bright }}$ cells (Hong et al., 2012), CD94 ${ }^{\text {bright }}$ CD56 ${ }^{\text {dim }}$ cells (Yu et al., 2010), and CD62L ${ }^{+}$CD56 ${ }^{\text {dim }}$ cells (Juelke et al., 2010). These studies reflect the dynamic nature of NK cell differentiation and emphasize the need for additional experimental evidence to rigorously establish the ontogeny of these subsets.

In summary, based on the available phenotypic and transcriptional profiling data, we suggest that the rmNK CD56 ${ }^{+}$ and $\mathrm{CD}_{16}{ }^{+}$populations bear a striking homology to their hNK CD56 ${ }^{\text {bright }}$ and CD56 ${ }^{\text {dim }}$ counterparts (Figure 2). Moreover, the rhesus DN NK cell population displays a distinctive pattern of gene expression that strongly suggests it represents an intermediate stage of differentiation between $\mathrm{CD}^{+} 6^{+}$and $\mathrm{CD} 16^{+} \mathrm{NK}$ cells.

\section{HUMAN AND NON-HUMAN PRIMATE NK CELLS IN HIV AND SIV INFECTION}

The discovery of simian immunodeficiency virus (SIV) in rhesus macaques with an acquired and transmissible immunodeficiency (Daniel et al., 1985) generated considerable interest in nonhuman primate species as disease models for HIV. Non-human primates have since served as an invaluable resource to study the pathogenesis of lentiviral infections and to test vaccine and treatment strategies against HIV (Van Rompay, 2012).

Multiple phenotypic and functional changes within the NK cell compartment have been documented in HIV infection (Fauci et al., 2005; Iannello et al., 2008) and many similar alterations have been identified in SIV infection (Bostik et al., 2010; Reeves et al., 2010). One of the hallmarks of HIV and pathogenic SIV infection is systemic immune activation of the host (Douek et al., 2009). This is reflected by the activation states of virtually all immune cells, including NK cells, as shown by increased expression of activation markers and functional hyperactivity as detected by increased frequencies of NK cells producing IFN- $\gamma$, TNF- $\alpha$ and enhanced degranulation and killing activity (Giavedoni et al., 2000; Alter et al., 2004; Fogli et al., 2004). Acute HIV and SIV infection were found to be associated with an initial expansion followed by a contraction of NK cells (Giavedoni et al., 2000; Alter et al., 2007). Although NK cells were generally shown to proliferate and die more rapidly than $\mathrm{T}$ cells in humans (Lutz et al., 2011), their turnover rates are further enhanced in chronic HIV infection (Kottilil et al., 2007). Increased NK cell turnover was also detected in SIV-infected rhesus macaques in a study in which NK cells were defined as $\mathrm{CD} 3^{-} \mathrm{CD} 8^{+} \mathrm{CD} 16^{+}$cells (De Boer 


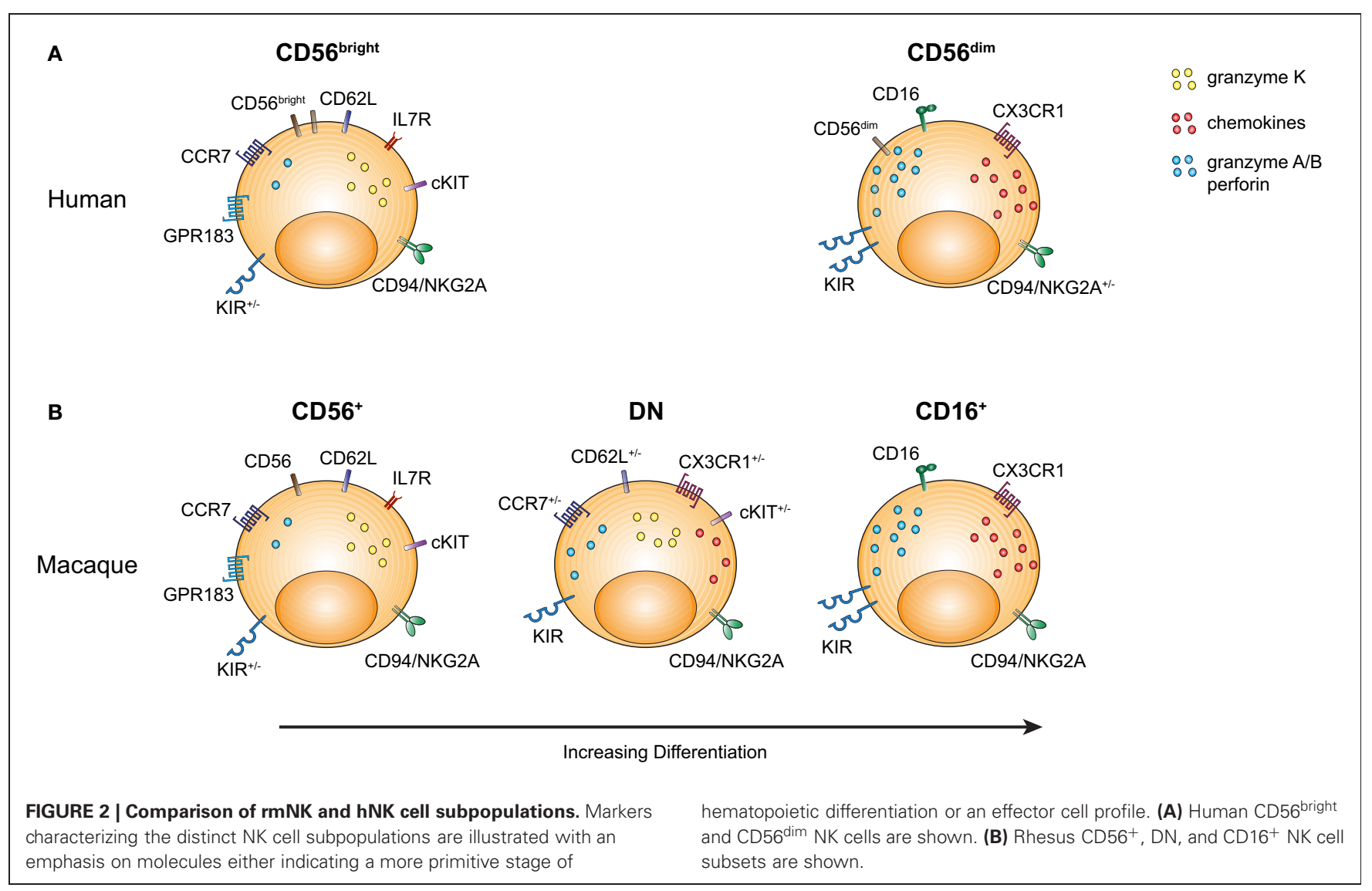

et al., 2003), although this gating strategy excludes the CD56 ${ }^{+}$and DN rmNK cell subpopulations, and may have limited the authors' ability to accurately assess the effects of SIV infection on the full repertoire of rmNK cells.

Although NK cells from chronically HIV- or SIV-infected donors display a hyper-activated state, their capacity to respond to PMA and ionomycin is diminished (Azzoni et al., 2002; Labonte et al., 2006). Furthermore, studies have demonstrated a dramatic skewing of NK cell subpopulations in peripheral blood during SIV and HIV infection. HIV infection was associated with a decrease of $\mathrm{CD} 56^{\mathrm{dim}} \mathrm{NK}$ cells and an increase of the $\mathrm{CD}^{-} 6^{-} \mathrm{CD} 16^{+} \mathrm{NK}$ cell subset (Alter et al., 2005; Mavilio et al., 2005b; Hong et al., 2010a,b), whereas SIV-infected macaques displayed an expansion of DN and CD16 ${ }^{+}$NK cells (Reeves et al., 2010). Interestingly, both HIV and SIV infection induced a loss of CCR7-expressing CD56 bright and $\mathrm{CD} 56^{+}$cells, respectively, without affecting the frequencies of cells expressing CD62L (Reeves et al., 2010; Hong et al., 2012). This perturbation was furthermore accompanied by an increased expression of granzyme B and perforin and elevated degranulation in response to MHC class I-devoid tumor cells (Mantegani et al., 2009). Importantly, there seems to be an inverse relationship between the severity of immune activation and/or viral load and the impact of viral infection on NK cells, as evidenced in natural host SIV infection in sooty mangabeys (Pereira et al., 2008) or non-viremic HIV-patients (Vieillard et al., 2010). Taken together, these studies provide solid evidence for SIV-induced perturbations in rmNK cells similar to what has been described in chronic HIV infection.

\section{NON-HUMAN PRIMATE STUDIES SHED LIGHT ON NK CELLS IN TISSUES}

Whereas most hNK studies have focused on NK cell subsets from peripheral blood, much less is known about NK cells in tissues. The complexity and heterogeneity of hNK cells residing in various organs, such as uterus, brain, spleen, liver, pancreas, and skin, as well as various mucosal tissues, including the gut, is an area of research that is garnering increasing interest (Shi et al., 2011). For obvious reasons, research is hindered by the significant limitations in obtaining human tissue samples. Here, we highlight one example of how studies on tissue-residing NK cells in non-human primates may lead to a better understanding of human diseases.

A novel IL-22- and IL-17-producing NKp44 ${ }^{+} \mathrm{hNK}$ cell subset was recently discovered in human and mouse mucosalassociated lymphoid tissues (Cella et al., 2009; Crellin et al., 2010). Unlike conventional NK cells, these lymphocytes do not display cytolytic activity but instead seem to be crucial for maintaining the integrity of epithelial tissues. Since HIV and SIV are predominantly transmitted and replicate in gut-associated lymphoid tissues (GALT), we and others sought to explore the role of IL-22-producing NK cells in SIV infection. SIV infection was associated with a substantial loss of IL-17- and IL-22-producing lymphocytes, 
including NKp44 ${ }^{+}$NK cells (Reeves et al., 2011; Klatt et al., 2012; $\mathrm{Xu}$ et al., 2012). Remarkably, the remaining NKp44${ }^{+}$NK cells displayed an altered functional profile with increasing resemblance to conventional NK cells. These alterations were linked to gut inflammation and the up-regulation of indoleamine 2,3dioxygenase 1 (Reeves et al., 2011). Given the importance of IL-17 and IL-22 for the maintenance of gut integrity and enterocyte homeostasis, these studies suggest a mechanistic explanation of how HIV and SIV infection damage the epithelium and subsequently drive disease progression.

A recent study described an expansion of intraepithelial and lamina propria $\mathrm{NKp} 46^{+} \mathrm{NK}$ cell subsets in treated HIV-patients with incomplete or suboptimal CD4 ${ }^{+} \mathrm{T}$ cell recovery (Sips et al., 2012). This finding suggests that gut mucosa-residing NKp46 ${ }^{+}$ NK cells could play a compensatory role in patients with ongoing compromised immunity. However, to our knowledge, the impact of HIV infection on IL-22-producing NKp $44^{+}$hNK cells has not yet been addressed.

\section{MANIPULATIONS OF THE NON-HUMAN PRIMATE IMMUNE SYSTEM}

In addition to improved access to tissue samples, a number of experimental procedures that have the potential to significantly advance our understanding of NK cells can be carried out in nonhuman primates. For instance, the in vivo effects of cytokines on lymphocyte homeostasis and disease can be addressed in rhesus macaques (Kuramoto et al., 2004; Waldmann et al., 2011). Administration of IL-15 resulted in an almost 3-fold increase of circulating NK cells in addition to increasing the number of effector memory $\mathrm{CD}^{+} \mathrm{T}$ cells (Mueller et al., 2005). Rhesus and cynomolgus macaque models have been a critical tool for the study of immune responses in the setting of transplantation (Kean et al., 2012). NK cells can be involved in both graft rejection and induction of tolerance (Kroemer et al., 2008). Efforts to therapeutically modulate NK cells to facilitate tolerance against allogeneic tissue grafts are likely to require further studies in animal models and, in particular, in non-human primates.

To evaluate the antiviral contributions of NK cells in control of SIV infection, mouse monoclonal antibodies against CD16 have been administered to rhesus macaques (Choi et al., 2008). There are several caveats to this approach, one of them being that the majority of tissue NK cells, in contrast to NK cells in peripheral blood, do not express CD16 (Reeves et al., 2010). Nonetheless, this study and other lymphocyte depletion studies (Schmitz et al., 1999), provide ample evidence that the depletion of selected

\section{REFERENCES}

Alter, G., Malenfant, J. M., Delabre, R. M., Burgett, N. C., Yu, X. G., Lichterfeld, M., et al. (2004). Increased natural killer cell activity in viremic HIV-1 infection. J. Immunol. 173, 5305-5311.

Alter, G., Teigen, N., Ahern, R., Streeck, H., Meier, A., Rosenberg, E. S., et al. (2007). Evolution of innate and adaptive effector cell functions during acute HIV-1 infection. J. Infect. Dis. 195, 1452-1460.
Alter, G., Teigen, N., Davis, B. T., Addo, M. M., Suscovich, T. J., Waring, M. T., et al. (2005). Sequential deregulation of NK cell subset distribution and function starting in acute HIV1 infection. Blood 106, 3366-3369.

Azzoni, L., Papasavvas, E., Chehimi, J., Kostman, J. R., Mounzer, K., Ondercin, J., et al. (2002). Sustained impairment of IFN-gamma secretion in suppressed HIV-infected patients despite mature NK cell recovery: evidence for a defective

lymphocyte populations, including NK cells, is possible and can thus be utilized to study their role in an in vivo setting.

Furthermore, non-human primates could also be used in autologous transfer studies using fluorescently labeled cells and ex vivo expanded cells. This approach could generate novel insights into NK cell turnover, differentiation, migratory behavior, in vivo killing of target cells, and other areas. Moreover, induced pluripotent stem cells have been used to generate hNK cells with antiviral activity against HIV (Knorr and Kaufman, 2010). NK cells derived from induced rhesus pluripotent stem cells (Liu et al., 2008) could be used to monitor in vivo NK cell development and differentiation. These and many other experimental manipulations of the immune system in nonhuman primates open a number of new avenues to address basic immunological questions and highlight the potential of these animal models.

\section{CONCLUSION}

Here we present two arguments as to why NK cell research in non-human primate models has the potential to yield significant insights into hNK biology. First, as a consequence of the phylogenetic relatedness of humans and non-human primates, there are many shared properties between hNK and non-human primate NK cells. Second, as an animal model, non-human primates offer access to tissues and allow a variety of manipulations, which the "human model" cannot offer due to ethical constraints. The work in non-human primates is challenging, as animals and their housing are relatively cost-intensive and require dedicated facilities and staff. Nonetheless, we believe that their significance as a disease model and the potential clinical applicability of immunological findings derived from these animals continue to make research in non-human primates highly rewarding.

Non-human primate models not only bear relevance for humans as outstanding disease models but also as a valuable resource to address basic immunological questions. The exciting answers to these questions and the lessons non-human primates can teach us certainly deserve a greater consideration by the scientific community.

\section{ACKNOWLEDGMENTS}

We thank Michelle Connole for her dedicated assistance with flow cytometric cell sorting. This work was supported by grants from the NIH (NEPRC base grant P51 OD011103; R01 AI090735 to R. Paul Johnson) and by the German Research Foundation (research stipend HO 4527/1-1 to Henoch S. Hong).

reconstitution of innate immunity. J. Immunol. 168, 5764-5770.

Bennett, I. M., Zatsepina, O., Zamai, L., Azzoni, L., Mikheeva, T., and Perussia, B. (1996). Definition of a natural killer NKR-P1A+/CD56/CD16- functionally immature human NK cell subset that differentiates in vitro in the presence of interleukin 12. J. Exp. Med. 184, 1845-1856.

Beziat, V., Duffy, D., Quoc, S. N., Le Garff-Tavernier, M., Decocq,
J., Combadiere, B., et al. (2011). CD56brightCD16+ NK cells: a functional intermediate stage of NK cell differentiation. J. Immunol. 186, 6753-6761.

Bostik, P., Takahashi, Y., Mayne, A. E., and Ansari, A. A. (2010). Innate immune natural killer cells and their role in HIV and SIV infection. HIV Ther. 4, 483-504.

Caligiuri, M. A. (2008). Human natural killer cells. Blood 112, 461-469. 
Carlyle, J. R., Mesci, A., Fine, J. H., Chen, P., Belanger, S., Tai, L. H., et al. (2008). Evolution of the Ly49 and Nkrpl recognition systems. Semin. Immunol. 20, 321-330.

Carter, D. L., Shieh, T. M., Blosser, R. L., Chadwick, K. R., Margolick, J. B., Hildreth, J. E., et al. (1999). CD56 identifies monocytes and not natural killer cells in rhesus macaques. Cytometry 37, 41-50.

Cella, M., Fuchs, A., Vermi, W., Facchetti, F., Otero, K., Lennerz, J. K., et al. (2009). A human natural killer cell subset provides an innate source of IL-22 for mucosal immunity. Nature 457, 722-725.

Choi, E. I., Reimann, K. A., and Letvin, N. L. (2008). In vivo natural killer cell depletion during primary simian immunodeficiency virus infection in rhesus monkeys. J. Virol. 82, 6758-6761.

Cooper, M. A., Fehniger, T. A., Turner, S. C., Chen, K. S., Ghaheri, B. A., Ghayur, T., et al. (2001). Human natural killer cells: a unique innate immunoregulatory role for the CD56(bright) subset. Blood 97, 3146-3151.

Crellin, N. K., Trifari, S., Kaplan, C. D., Cupedo, T., and Spits, H. (2010). Human NKp44+IL-22+ cells and LTi-like cells constitute a stable RORC+ lineage distinct from conventional natural killer cells. J. Exp. Med. 207, 281-290.

Daniel, M. D., Letvin, N. L., King, N. W., Kannagi, M., Sehgal, P. K., Hunt, R. D., et al. (1985). Isolation of T-cell tropic HTLV-III-like retrovirus from macaques. Science 228, 1201-1204.

Davis, M. M. (2008). A prescription for human immunology. Immunity 29, 835-838.

De Boer, R. J., Mohri, H., Ho, D. D., and Perelson, A. S. (2003). Turnover rates of $\mathrm{B}$ cells, $\mathrm{T}$ cells, and $\mathrm{NK}$ cells in simian immunodeficiency virus-infected and uninfected rhesus macaques. J. Immunol. 170, 2479-2487.

Douek, D. C., Roederer, M., and Koup, R. A. (2009). Emerging concepts in the immunopathogenesis of AIDS. Annu. Rev. Med. 60, 471-484.

Eagle, R. A., and Trowsdale, J. (2007). Promiscuity and the single receptor: NKG2D. Nat. Rev. Immunol. 7, 737-744.

Fauci, A. S., Mavilio, D., and Kottilil, S. (2005). NK cells in HIV infection: paradigm for protection or targets for ambush. Nat. Rev. Immunol. 5, 835-843.

Fogli, M., Costa, P., Murdaca, G., Setti, M., Mingari, M. C., Moretta, L., et al. (2004). Significant NK cell activation associated with decreased cytolytic function in peripheral blood of HIV-1-infected patients. Eur. J. Immunol. 34, 2313-2321.

Giavedoni, L. D., Velasquillo, M. C., Parodi, L. M., Hubbard, G. B., and Hodara, V. L. (2000). Cytokine expression, natural killer cell activation, and phenotypic changes in lymphoid cells from rhesus macaques during acute infection with pathogenic simian immunodeficiency virus. J. Virol. 74, 1648-1657.

Hanna, J., Bechtel, P., Zhai, Y., Youssef, F., McLachlan, K., and Mandelboim, O. (2004). Novel insights on human NK cells' immunological modalities revealed by gene expression profiling. J. Immunol. 173, 6547-6563.

Hayakawa, Y., Huntington, N. D., Nutt, S. L., and Smyth, M. J. (2006). Functional subsets of mouse natural killer cells. Immunol. Rev. 214, 47-55.

Hayakawa, Y., and Smyth, M. J. (2006). CD27 dissects mature NK cells into two subsets with distinct responsiveness and migratory capacity. J. Immunol. 176, 1517-1524.

Hong, H. S., Ahmad, F., Eberhard, J. M., Bhatnagar, N., Bollmann, B. A., Keudel, P., et al. (2012). Loss of CCR7 expression on CD56(bright) NK cells is associated with a CD56(dim)CD16(+) NK cell-like phenotype and correlates with HIV viral load. PLOS ONE 7:e44820. doi: 10.1371/journal.pone.0044820

Hong, H. S., Eberhard, J. M., Keudel, P., Bollmann, B. A., Ahmad, F., Ballmaier, M., et al. (2010a). Phenotypically and functionally distinct subsets contribute to the expansion of CD56-/CD16+ natural killer cells in HIV infection. AIDS 24, 1823-1834.

Hong, H. S., Eberhard, J. M., Keudel, P., Bollmann, B. A., Ballmaier, M., Bhatnagar, N., et al. (2010b). HIV infection is associated with a preferential decline in less-differentiated CD56dim CD16+ NK cells. J. Virol. 84, 1183-1188.

Iannello, A., Debbeche, O., Samarani, S., and Ahmad, A. (2008). Antiviral NK cell responses in HIV infection: II. viral strategies for evasion and lessons for immunotherapy and vaccination. J. Leukoc. Biol. $84,27-49$.

Juelke, K., Killig, M., Luetke-Eversloh, M., Parente, E., Gruen, J., Morandi, B., et al. (2010). CD62L expression identifies a unique subset of polyfunctional CD56dim NK cells. Blood 116, 1299-1307.

Karre, K., Ljunggren, H. G., Piontek, G., and Kiessling, R. (1986).
Selective rejection of $\mathrm{H}$-2-deficient lymphoma variants suggests alternative immune defence strategy. Nature 319, 675-678.

Kean, L. S., Singh, K., Blazar, B. R., and Larsen, C. P. (2012). Nonhuman primate transplant models finally evolve: detailed immunogenetic analysis creates new models and strengthens the old. Am. J. Transplant. 12, 812-819.

Khakoo, S. I., Thio, C. L., Martin, M. P., Brooks, C. R., Gao, X., Astemborski, J., et al. (2004). HLA and NK cell inhibitory receptor genes in resolving hepatitis $\mathrm{C}$ virus infection. Science 305, 872-874.

Klatt, N. R., Estes, J. D., Sun, X., Ortiz, A. M., Barber, J. S., Harris, L. D., et al. (2012). Loss of mucosal CD103+ DCs and IL-17+ and IL-22+ lymphocytes is associated with mucosal damage in SIV infection. Mucosal Immunol. 6, 646-657.

Knorr, D. A., and Kaufman, D. S. (2010). Pluripotent stem cellderived natural killer cells for cancer therapy. Transl. Res. 156, 147-154.

Kottilil, S., Jackson, J. O., Reitano, K. N., O'Shea, M. A., Roby, G., Lloyd, M., et al. (2007). Innate immunity in HIV infection: enhanced susceptibility to CD95-mediated natural killer cell death and turnover induced by HIV viremia. J. Acquir. Immune Defic. Syndr. 46, 151-159.

Kroemer, A., Edtinger, K., and Li, X. C. (2008). The innate natural killer cells in transplant rejection and tolerance induction. Curr. Opin. Organ Transplant. 13, 339-343.

Kuramoto, K., Follmann, D. A., Hematti, P., Sellers, S., Agricola, B. A., Metzger, M. E., et al. (2004). Effect of chronic cytokine therapy on clonal dynamics in nonhuman primates. Blood 103, 4070-4077.

Labonte, M. L., McKay, P. F., and Letvin, N. L. (2006). Evidence of NK cell dysfunction in SIV-infected rhesus monkeys: impairment of cytokine secretion and $\mathrm{NKG} 2 \mathrm{C} / \mathrm{C} 2$ expression. Eur. J. Immunol. 36, 2424-2433.

Lanier, L. L. (2008). Evolutionary struggles between NK cells and viruses. Nat. Rev. Immunol. 8, 259-268.

Lanier, L. L., Le, A. M., Civin, C. I., Loken, M. R., and Phillips, J. H. (1986). The relationship of CD16 (Leu-11) and Leu-19 (NKH-1) antigen expression on human peripheral blood NK cells and cytotoxic $\mathrm{T}$ lymphocytes. J. Immunol. 136, 4480-4486.

Liu, H., Zhu, F., Yong, J., Zhang, P., Hou, P., Li, H., et al. (2008). Generation of induced pluripotent stem cells from adult rhesus monkey fibroblasts. Cell Stem Cell 3, 587-590.

Ljunggren, H. G., and Karre, K. (1990), In search of the 'missing self': MHC molecules and NK cell recognition. Immunol. Today 11, 237-244.

Lutz, C. T., Karapetyan, A., Al-Attar, A., Shelton, B. J., Holt, K. J., Tucker, J. H., et al. (2011). Human NK cells proliferate and die in vivo more rapidly than $\mathrm{T}$ cells in healthy young and elderly adults. J. Immunol. 186, 4590-4598.

Mantegani, P., Tambussi, G., Galli, L., Din, C. T., Lazzarin, A., and Fortis, C. (2009). Perturbation of the natural killer cell compartment during primary human immunodeficiency virus 1 infection primarily involving the CD56 bright subset. Immunology 129, 220-233.

Martin, M. P., Gao, X., Lee, J. H., Nelson, G. W., Detels, R., Goedert, J. J., et al. (2002). Epistatic interaction between KIR3DS1 and HLA-B delays the progression to AIDS. Nat. Genet. 31, 429-434.

Martin, M. P., Qi, Y., Gao, X., Yamada, E., Martin, J. N., Pereyra, F., et al. (2007). Innate partnership of HLA$B$ and KIR3DL1 subtypes against HIV-1. Nat. Genet. 39, 733-740.

Mavilio, D., Benjamin, J., Kim, D., Lombardo, G., Daucher, M., Kinter, A., et al. (2005a). Identification of NKG2A and NKp80 as specific natural killer cell markers in rhesus and pigtailed monkeys. Blood 106, 1718-1725.

Mavilio, D., Lombardo, G., Benjamin, J., Kim, D., Follman, D., Marcenaro, E., et al. (2005b). Characterization of CD56-/CD16+ natural killer (NK) cells: a highly dysfunctional NK subset expanded in HIV-infected viremic individuals. Proc. Natl. Acad. Sci. U.S.A. 102, 2886-2891.

Mestas, J., and Hughes, C. C. (2004). Of mice and not men: differences between mouse and human immunology. J. Immunol. 172, 2731-2738.

Mueller, Y. M., Petrovas, C., Bojczuk, P. M., Dimitriou, I. D., Beer, B., Silvera, P., et al. (2005). Interleukin15 increases effector memory CD8+ $t$ cells and NK Cells in simian immunodeficiency virus-infected macaques. J. Virol. 79, 4877-4885.

Natarajan, K., Dimasi, N., Wang, J., Mariuzza, R. A., and Margulies, D. H. (2002). Structure and function of natural killer cell receptors: multiple molecular solutions to self, nonself discrimination. Annu. Rev. Immunol. 20, 853-885. 
Orange, J. S. (2006). Human natural killer cell deficiencies. Curr. Opin. Allergy Clin. Immunol. 6, 399-409.

Pascal, V., Stulberg, M. J., and Anderson, S. K. (2006). Regulation of class I major histocompatibility complex receptor expression in natural killer cells: one promoter is not enough! Immunol. Rev. 214, 9-21.

Paust, S., Gill, H. S., Wang, B. Z., Flynn, M. P., Moseman, E. A., Senman, B., et al. (2010). Critical role for the chemokine receptor CXCR6 in NK cell-mediated antigen-specific memory of haptens and viruses. Nat. Immunol. 11, 1127-1135.

Pereira, L. E., Johnson, R. P., and Ansari, A. A. (2008). Sooty mangabeys and rhesus macaques exhibit significant divergent natural killer cell responses during both acute and chronic phases of SIV infection. Cell. Immunol. 254, 10-19.

Raulet, D. H. (2003). Roles of the NKG2D immunoreceptor and its ligands. Nat. Rev. Immunol. 3, 781-790.

Reeves, R. K., Gillis, J., Wong, F. E., Yu, Y., Connole, M., and Johnson, R. P. (2010). CD16- natural killer cells: enrichment in mucosal and secondary lymphoid tissues and altered function during chronic SIV infection. Blood 115, 4439-4446.

Reeves, R. K., Rajakumar, P. A., Evans, T. I., Connole, M., Gillis, J., Wong, F. E., et al. (2011). Gut inflammation and indoleamine deoxygenase inhibit IL-17 production and promote cytotoxic potential in NKp44+ mucosal NK cells during SIV infection. Blood 118, 3321-3330.

Romagnani, C., Juelke, K., Falco, M., Morandi, B., D’Agostino, A., Costa, R., et al. (2007). CD56brightCD16killer Ig-like receptor- NK cells display longer telomeres and acquire features of CD56dim NK cells upon activation. J. Immunol. 178, 4947-4955.

Schmitz, J. E., Kuroda, M. J., Santra, S., Sasseville, V. G., Simon, M. A., Lifton, M. A., et al. (1999). Control of viremia in simian immunodeficiency virus infection by CD8+ lymphocytes. Science 283, 857-860.

Shi, F. D., Ljunggren, H. G., La Cava, A., and Van Kaer, L. (2011). Organ-specific features of natural killer cells. Nat. Rev. Immunol. 11, 658-671.

Sips, M., Sciaranghella, G., Diefenbach, T., Dugast, A. S., Berger, C. T., Liu, Q., et al. (2012). Altered distribution of mucosal NK cells during HIV infection. Mucosal Immunol. 5, 30-40.

Sun, J. C., Beilke, J. N., and Lanier, L. L. (2009). Adaptive immune features of natural killer cells. Nature 457, 557-561.

Van Rompay, K. K. (2012). The use of nonhuman primate models of HIV infection for the evaluation of antiviral strategies. AIDS Res. Hum. Retroviruses 28, 16-35.

Vieillard, V., Fausther-Bovendo, H., Samri, A., and Debre, P. (2010). Specific phenotypic and functional features of natural killer cells from HIV-infected long-term nonprogressors and HIV controllers. J. Acquir. Immune Defic. Syndr. 53, 564-573.

Vosshenrich, C. A., Garcia-Ojeda, M. E., Samson-Villeger, S. I., Pasqualetto, V., Enault, L., RichardLe Goff, O., et al. (2006). A thymic pathway of mouse natural killer cell development characterized by expression of GATA-3 and CD127. Nat. Immunol. 7, 1217-1224.

Waldmann, T. A., Lugli, E., Roederer, M., Perera, L. P., Smedley, J. V. Macallister, R. P., et al. (2011). Safety (toxicity), pharmacokinetics, immunogenicity, and impact on elements of the normal immune system of recombinant human IL15 in rhesus macaques. Blood 117, 4787-4795.

Webster, R. L., and Johnson, R. P. (2005). Delineation of multiple subpopulations of natural killer cells in rhesus macaques. Immunology 115 , 206-214.

Xu, H., Wang, X., Liu, D. X., MoroneyRasmussen, T., Lackner, A. A. and Veazey, R. S. (2012). IL-17producing innate lymphoid cells are restricted to mucosal tissues and are depleted in SIV-infected macaques. Mucosal Immunol. 6, 658-669.
Yu, J., Mao, H. C., Wei, M., Hughes, T., Zhang, J., Park, I. K., et al. (2010). CD94 surface density identifies a functional intermediary between the CD56bright and CD56dim human NK-cell subsets. Blood 115, 274-281.

Conflict of Interest Statement: The authors declare that the research was conducted in the absence of any commercial or financial relationships that could be construed as a potential conflict of interest.

Received: 31 October 2012; paper pending published: 20 December 2012; accepted: 27 January 2013; published online: 18 February 2013.

Citation: Hong HS, Rajakumar PA, Billingsley JM, Reeves RK and Johnson RP (2013) No monkey business: why studying NK cells in non-human primates pays off. Front. Immun. 4:32. doi: 10.3389/fimmu.2013.00032

This article was submitted to Frontiers in NK Cell Biology, a specialty of Frontiers in Immunology.

Copyright (c) 2013 Hong, Rajakumar, Billingsley, Reeves and Johnson. This is an open-access article distributed under the terms of the Creative Commons Attribution License, which permits use, distribution and reproduction in other forums, provided the original authors and source are credited and subject to any copyright notices concerning any third-party graphics etc. 